\title{
“EMENTAS DE DISCIPLINAS COM O TERMO “LAZER” EM INSTITUIÇÕES DE ENSINO SUPERIOR DE CURITIBA: DIFERENÇAS E SIMILIDARIDADES
}

Talita Stresser de Assis*

Andreia Juliane Drula**

\begin{abstract}
RESUMO
Buscamos identificar as possíveis diferenças e similaridades nas ementas de disciplinas com o termo "lazer" em três universidades de Curitiba. Selecionamos os cursos de Educação Física e o critério de escolha de disciplinas foi a presença do termo "lazer" no título. Percebemos diferenças em relação à carga horária, número de disciplinas, utilização de diferentes termos e tipos de formação que se pretendem. Como similaridades, observamos a predominância de disciplinas nos cursos de Bacharelado e o estudo do histórico do lazer. Por fim, indicamos análise dos planos de ensino e da prática docente para melhor aprofundamento.
\end{abstract}

Palavras-chave: Formação profissional. Lazer. Universidade.

\section{INTRODUÇÃO}

Os estudos do fenômeno lazer remontam à primeira metade do século XX, e neles já é possível identificar concepções de lazer em voga naquele período histórico. No entanto, o repensar sobre o lazer no Brasil tornou-se mais intenso na década de 1970. (GOMES, 2004). Hoje, percebemos que os diversos autores que versam sobre esse tema possuem diferentes perspectivas teóricas, perspectivas essas que podem contemplar um viés marxista, fenomenológico, mercadológico, entre outros. Essas perspectivas podem influenciar os sujeitos que tem contato com esse tema, principalmente os que estão dentro do meio acadêmico.

Nesse contexto, temos o estudo do lazer dentro das Universidades, a partir de projetos de pesquisa e/ou extensão e as disciplinas de graduação e pós-graduação. Sabemos que, a partir da década de 1970, a comunidade acadêmica relevou a discussão acerca das diversas faces do lazer, principalmente em cursos como Educação Física, Turismo e Pedagogia (ISAYAMA, 2002). Há também cursos de mestrado e doutorado especificamente na área de lazer, como na UFMG, Unicamp, UEL entre outras.

Em relação à graduação, percebemos que não se tem uma formação "unificada" relacionada ao tema lazer, pois cada Universidade pode construir seu próprio plano de curso e os planos de ensino são desenvolvidos por cada professor responsável e submetidos à aprovação dos outros docentes do curso. Dessa forma, os sujeitos formados pelas diferentes Universidades do Brasil podem possuir diferentes perspectivas sobre o mesmo tema, pois sua formação está sujeita às concepções teóricas e políticas da Universidade, do seu 
curso de graduação, dos docentes e até dos colegas do curso, nos quais, muitas vezes, priorizam a prática gerando uma formação tecnicista (MARIN, 2001).

No entanto, sabemos que essas questões relacionadas ao lazer possuem também outros fatores que podem influenciar a formação profissional da área, seja voltada para o mercado de consumo ou construção de um ser crítico e criativo, dentre outros, que podem gerar diferenças e similaridades. Nesse sentido, temos como pergunta norteadora desse trabalho: quais as diferenças e similaridades apresentadas nas ementas de disciplinas com o termo "lazer" em diferentes Instituições de Ensino Superior de Curitiba?

Assim sendo, o objetivo desse estudo é identificar as possíveis diferenças e similaridades nas ementas de disciplinas com o termo "lazer" presente no título em três Instituições de Ensino Superior de Curitiba, sendo uma privada e duas públicas federais. Para tanto, buscamos referencias teóricos sobre o tema proposto. Posteriormente, realizamos a análise das ementas das instituições pesquisadas e por fim desenvolvemos categorias a partir de suas diferenças e similaridades.

A partir desse estudo poderão ser identificadas as perspectivas atreladas às disciplinas com o termo "lazer" e sua relação com as Instituições de Ensino Superior de Curitiba que estão inseridas, assim como avançar nas discussões sobre o tema.

\section{PROCEDIMENTOS METODOLÓGICOS}

Esta pesquisa foi desenvolvida em uma abordagem qualitativa utilizando-se para tanto os seguintes instrumentos metodológicos:

a) Revisão de literatura sobre a temática em questão;

b) Seleção de três Instituições de Ensino Superior de Curitiba para coleta das ementas de disciplinas com o termo "lazer";

c) Coleta das ementas de disciplinas com o termo "lazer" das Instuições selecionadas;

d) Análise das ementas coletadas.

A revisão de literatura, item (a), foi desenvolvida a partir da busca em base de dados pelos termos: formação profissional no lazer, currículo no lazer, concepções de lazer e disciplinas de lazer. As bases de dados utilizadas foram: Periódicos CAPES, Biblioteca Digital de Teses e Dissertações da UNICAMP, Scielo, Google Acadêmico, Revista Brasileira de Ciências do Esporte (RBCE) e Revista Movimento. Quando percebemos que havia certa incidência de resultados do mesmo autor buscamos seu Currículo Lattes para encontrar novos trabalhos.

Para a seleção das três Instituições de Ensino Superior, item (b), foi utilizado como critério as três universidades melhores ranqueadas no Índice Geral 
de Cursos do ENADE - $2010^{1}$ sendo que duas são públicas federais (Universidade $A$ e B) e uma é privada (Universidade $C$ ).

$\mathrm{Na}$ coleta das ementas, item (c), buscamos os Cursos de Educação Física das instituições selecionadas e o critério de escolha de disciplinas foi a presença do termo "lazer" no seu título. A partir disso, buscamos nos sites de cada Instituição a grade curricular dos cursos de Educação Física e coletamos as ementas dos sites, sendo somente a Universidade C solicitada ao coordenador do curso a ementa desejada, assim obtivemos três disciplinas na Universidade $A$, uma na Universidade $B$ e uma disciplina dividida em dois módulos na Universidade C. É importante frisar que apenas a Universidade A apresenta uma disciplina que está contemplada no curso de Licenciatura em Educação Física, a mesma disciplina também está na grade curricular do curso de Bacharelado em Educação Física da mesma Universidade.

No caso do item (d), para análise das ementas buscamos palavras e termos "padrões" para entender a relação de diferença ou similaridade entre as ementas, assim como procuramos outros dados relevantes, tais como: o nome da disciplina, a carga horária da disciplina e o período em que está inclusa na grade curricular do curso.

A partir de tal análise, juntamente com apoio da literatura, tivemos subsídios para identificar as diferenças e similaridades apresentadas pelas ementas e criar categorias de análise: carga horária e quantidade das disciplinas; utilização de diferentes termos; tipos de formação que se pretendem; disciplinas com o termo "lazer" e os cursos de licenciatura e bacharelado; o estudo do histórico do lazer.

\section{PRÉVIA ANÁLISE DAS EMENTAS}

A primeira universidade analisada, denominada Universidade A é de caráter público e apresentou o maior número de disciplinas com o termo "lazer" em seu nome: Fundamentos do Lazer (60 horas - 3ำ período na Licenciatura e $4^{\circ}$ período no Bacharelado), Atuação Profissional no Lazer (60 horas -7ํㅜ período) e Políticas Públicas para o Esporte e Lazer (60 horas - 7ํㅜ período), apresentando, respectivamente, tais ementas: Principais correntes teóricas e tendências histórico-culturais do lazer
e suas relações com a área de Educação Física no âmbito escolar e
não escolar. (Ementa Fundamentos do Lazer, Universidade A).

Prática profissional no Lazer e as possibilidades de intervenção nos diferentes campos de atuação. (Ementa Atuação Profissional do Lazer, Universidade A).

\footnotetext{
1 ENADE - Exame Nacional de Desempenho dos Estudantes realizado em 2010. As Instituições de Ensino Superior foram selecionadas de acordo com o ranking de números contínuos e de faixa apresentados em Diários Oficiais do site http://portal.inep.gov.br/indicegeral-de-cursos.
} 
Sistemas políticos e ações governamentais para o Esporte e o Lazer. (Ementa Políticas Públicas para o Esporte e Lazer, Universidade A).

A Universidade B, pública, apresentou somente uma disciplina: Recreação e Lazer (60 horas - 3ํperíodo) com a seguinte ementa:

Caracterização, histórico e concepções de recreação e lazer nas diferentes sociedades; vivencias do lazer e recreação; classificação dos conteúdos culturais do lazer e das atividades recreativas; o papel do recreador e animador cultural e políticas públicas de recreação e lazer. (Ementa Recreação e Lazer, Universidade B).

Nessa ementa aparece um novo termo que não apareceu em nenhuma das disciplinas da Universidade A, o termo recreação e alguns de seus derivados, como atividades recreativas e recreador.

Por fim, a Universidade C de cunho privado, expôs a disciplina Recreação e Lazer Comunitário I e /l em que é subdividida em dois módulos (36 horas cada - o módulo I no $7^{\circ}$ período e o II no $8^{\circ}$ período), determinada pela ementa a seguir:

Analisar as relações entre lazer e trabalho na sociedade contemporânea, relacionando os aspectos filosóficos, as principais características do profissional do lazer e dos cursos de formação na área do lazer e da recreação. Aplicação prática de projetos, programas e eventos relacionados ao lazer e às atividades recreativas em instituições não formais (públicas e privadas). Organização e análise dos programas e atividades de recreação para clientes especiais e comunidade. ( $E$ menta Recreação e Lazer Comunitário I e II, Universidade C).

As três Universidades abordadas compartilham a mesma duração do curso de Educação Física, sendo de quatro anos (oito períodos). Outro importante dado a ser destacado é que somente a Universidade A oferta uma disciplina (Fundamentos do Lazer) para o curso de Licenciatura em Educação Físi$\mathrm{ca}$, todas as demais disciplinas analisadas estão na grade curricular do Bacharelado em Educação Física, podendo ressaltar a defasagem que a formação na Licenciatura tem na área do lazer.

\section{DE EMENTAS PARA CATEGORIAS DE ANÁLISE}

A formação do profissional para a atuação no lazer engloba diversas vertentes que vão além do campo acadêmico, desenvolvendo um profissional que possa atuar em diferentes espaços, com diversas possibilidades de atuação, embasados em teorias expostas nas disciplinas da graduação que atendam as mudanças que ocorrem na sociedade, sejam no modo de vida ou de ser (FREITAS; CARVALHO, 2005). Para tanto, se faz necessária uma formação que abranja conhecimento ampliado e crítico, independente se o campo de atuação tenha ênfase no mercado ou no meio pedagógico. Quando analisadas as ementas das disciplinas selecionadas se evidenciaram similaridades e diferenças entre elas, seja pela linha tecnicista/prática ou pela abordagem mais 
teórica, dentre outras. Faz-se necessária uma categorização destes pontos destacados para a compreensão da formação que ocorre em tais Universidades de Curitiba. É importante frisar que estamos fazendo inferências a partir da análise das ementas, a realidade de cada disciplina pode ser muito diversa, pois depende da formação do docente, da Universidade e da própria forma de condução de cada aula.

Como ponto de partida, a questão numérica de disciplinas se faz pertinente, como também a carga horária de cada uma. A Universidade A dispõe de três disciplinas distintas com 60 horas cada, abordando diferentes enfoques em cada disciplina: uma teórica, uma prática e outra sobre ações de políticas públicas. Contrastando com a Universidade B, a qual oferta uma disciplina de 60 horas que contempla os três enfoques, e com a Universidade $C$, que intensifica a relação do lazer e trabalho em 72 horas totais. É possível verificar que a Universidade A desenvolve cerca de 100 horas a mais em estudos na área do lazer que as outras Universidades. Entretanto, não se pode questionar a qualidade que as Universidades B e C propõem tais disciplinas, necessitando de uma pesquisa in locu para tal questionamento, mesmo que não analisado este quesito, a Universidade A gera uma maior carga teórico/prática sobre a temática.

Mesmo com uma das universidades estudando os enfoques por mais horas, é importante a abrangência sobre o lazer nas três instituições. Como aponta Marin (2001), a compreensão sobre o lazer é e deve ser feita além de considerá-lo um objeto, mas um sujeito que é atento com as relações sociais, econômicas e históricas num âmbito global, na busca de um maior entendimento e formação de um profissional, que segundo Melo (2003), sobressaia de uma atuação com limitações e respaldada no senso comum.

Seguindo a linha de formação para atuação do profissional na sociedade, a Universidade $C$ traz em sua ementa uma consideração única dentre as instituições analisadas: "Organização e análise dos programas e atividades de recreação para clientes especiais e comunidade". A relação de oferecer atividades a clientes especiais com a Universidade $C$ ser privada gera uma reflexão da disciplina que pode se caracterizar como instrumental, podendo formar um profissional "pronto" para mercado de trabalho, e assim, consequentemente, aos seus clientes. Nesta direção, duas ressalvas são vitais, a primeira, que segundo Melo (2003), a formação deve atender as imediatas cargas de trabalho que a sociedade necessita e conseguindo interferir no mercado e na ordem social a partir do que foi aprendido no curso de graduação, "mas também para o emergente e ainda para os espaços de intervenção em pesquisa e formulação de políticas públicas para a área específica" (FREITAS; CARVALHO, 2003, p. 160). A segunda ressalva se dá pela separação de "clientes especiais e comunidade", em que pode demonstrar ações dicotômicas, porém, num contexto geral, a área do lazer deve ter entendido "como construção compartilhada por todos os sexos, idades, etnias, camadas sociais e sujeitos portadores de necessidades diversas" (Pinto, 2001 p. 61), em busca de uma sociedade justa e igual a todos. 
Outra observação pertinente é a utilização da nomenclatura "recreação" e seus derivados (recreador, atividades recreativas) em disciplinas da Universidade B e C. De origem norte-americana (MELO, 2003), o termo recreação é utilizado em disciplinas ligada ao lazer há muitos anos. A partir da década de 90 o termo "lazer" fez-se presente na grade curricular, "essa introdução foi impulsionada pela reformulação dos currículos desses cursos, que ocorreu em função da Resolução n.03/87, passando a denominar muitas disciplinas com os termos "recreação e lazer"' (ISAYAMA, 2002, p.47). Mas qual proporção o termo "recreação" se torna tão importante quanto o do "lazer"? Gaelzer (1979, p. 59) concebe a recreação como

\begin{abstract}
uma experiência na qual o indivíduo participa por escolha, devido ao prazer e à satisfação pessoal que obtém diretamente dela. Atividade recreativa é atividade que não seja conscientemente executada com o propósito de obter recompensa além da mesma, proporcionando ao homem um escape para as suas forças físicas, criadoras, e na qual ele participa por desejo íntimo e não por compulsão externa.
\end{abstract}

E é no tempo de lazer que um sujeito exerce a recreação. Há diversas abordagens no lazer, mas a recreação é sempre igualada ou usada conjuntamente ao termo "lazer". Essa análise se fez necessária quando vista que nas Universidades B e C o termo "Recreação" é vista em suas nomenclaturas das disciplinas, enquanto na Universidade A o termo não consta. Esta diferença pode estar relacionada com as mudanças contemporâneas que os cursos de Educação Física acarretaram ao longo dos anos para melhor compreender e estudar este fenômeno social, afastando da nomenclatura a recreação sendo que o "termo tende mais a restringir a complexidade da temática do que a ampliá-la" (MELO, 2003, p. 127) e fomentando diferentes disciplinas que trabaIhem não apenas o aspecto prático de atividades, mas disciplinas pautadas em estudar a teoria, com um projeto político-emancipatório, para atuação profissional em espaços públicos e privados, com intuito de atender toda a sociedade com o melhor conhecimento sobre a temática do lazer.

Em relação às similaridades, a primeira que percebemos em todas as ementas foi o estudo sobre o histórico-cultural do lazer. Sabemos que grande parte das disciplinas trabalha com esse enfoque, principalmente em seu início, como forma de contextualizar o estudo de determinado fenômeno. No entanto, salientamos a importância de entender como se dá esse processo, já que pode ser esvaziado de sentido e significado dependendo da ação pedagógica do docente.

Outra semelhança entre as ementas é a predominância de disciplinas com o termo "lazer" nos cursos de Bacharelado em Educação Física. Isso nos remete à fragmentação/divisão da formação em Educação Física que foi aprovada em 31 de março de 2004 pela resolução no 07 do Conselho Nacional de Educação (CNE). A divisão ocorreu, principalmente, pela insatisfação com o currículo da licenciatura plena por uma parcela corporativista da área, pelas justificativas de ser extensa e ultrapassada, com o argumento de que a licenci- 
atura não contemplava as competências dos campos não escolares, onde estavam seus interesses. (GARCIA, 2010).

Entendemos que a divisão entre licenciatura e bacharelado proporciona uma formação fragmentada do conhecimento, causando a desqualificação do sujeito em formação e do trabalhador na sua atuação profissional fazendo com que percam noção de totalidade. Essa separação passou a representar uma formação meramente pedagógica para a licenciatura e uma formação puramente técnica para o bacharelado.

Nesse sentido, podemos perceber que o estudo do lazer pode ser visto de forma técnica, já que está predominantemente nos cursos de bacharelado. Será que os sujeitos em formação na área da licenciatura não precisam desse conhecimento? Entendemos que essa falta de disciplinas com o conteúdo do lazer nos cursos de licenciatura podem gerar grandes prejuízos para os sujeitos em formação, assim como para seus futuros alunos.

\section{CONSIDERAÇÕES FINAIS}

A partir da análise das ementas, percebemos diferenças em relação à carga horária e quantidade das disciplinas, utilização de diferentes termos e tipos de formação que se pretendem. Em relação às similaridades, observamos principalmente a predominância de disciplinas com o termo "lazer" nos cursos de Bacharelado em Educação Física e o estudo do histórico do lazer.

Algumas diferenças podem nos indicar, principalmente, a importância que cada universidade estudada dá ao tema lazer, assim como a semelhança relacionada às disciplinas com o termo "lazer" e os cursos de licenciatura e bacharelado pode revelar uma dificuldade mais ampla que contempla os currículos dos cursos de Educação Física como um todo e "a partir da contribuição dessas várias ciências e disciplinas, pode constituir-se então um corpo de conhecimento especifico sobre o Lazer no mundo contemporâneo" (VALENTE, 1993, p.10) auxiliando para uma melhor formação do profissional.

Tal formação que agregada não somente aos aspectos práticos e técnicos que a atuação solicita, mas que "propõe uma formação centrada no conhecimento, na cultura e na crítica, concretizando-se por meio da construção de saberes e competências alicerçados no comprometimento com os valores disseminados numa sociedade democrática, bem como na compreensão do papel social do profissional na educação para e pelo lazer" (ISAYAMA, 2004, p. 94), saberes e competências, esses que, compreendidos e interiorizados através de disciplinas, sejam elas na graduação, pós-graduação ou cursos específico de lazer.

Entendemos que essa pesquisa não se encerra nesse trabalho, pois 0 mesmo é um "pontapé" inicial para uma análise mais profunda das disciplinas e das universidades. Dessa forma, propomos como encaminhamento a análise dos planos de ensino, dos conteúdos, da prática docente das disciplinas estudadas e da missão que a Universidade preza ao formar seus profissionais. 


\section{REFERÊNCIAS}

FREITAS, Fabiana Fernandes; CARVALHO, Yara Maria de. Lazer: discussões acerca da formação do profissional de educação física. Motrivivênvia, v. 27, n. 25, p. 151-162, dez. 2005. Disponível em: <http://www.periodicos.ufsc.br/index.php/motrivivencia/article/view/4700/3878 >. Acesso em: 07/05/2012.

GAELZER, Lenea. Lazer: bênção ou maldição?. Porto Alegre: Sulina: URGS, 1979.

GARCIA, Jeferson Diogo de Andrade. Reflexões acerca das diretrizes curriculares para a Educação Física: contexto, formação e atuação de professores em questão. EFDeportes, v. 15, n. 147, ago. 2010. Disponível em: <http://www.efdeportes.com/efd147/acerca-das-diretrizes-curriculares-para-aeducacao-fisica.htm>. Acesso em: 07/05/2012.

GOMES, Christianne Luce. Lazer - concepções. In: GOMES, Christianne Luce (Org.). Dicionário crítico do lazer. Belo Horizonte: Autêntica, 2004.

ISAYAMA, Hélder Ferreira. Recreação e lazer como integrantes de currículos dos cursos de graduação em educação física. Tese (Doutorado em Educação Física) - Faculdade de Educação Física, Universidade Estadual de Campinas, 2002.

ISAYAMA, Hélder Ferreira. Formação Profissional. In: GOMES, Christianne Luce (Org.). Dicionário crítico do lazer. Belo Horizonte: Autêntica, 2004.

MARIN, Elizara Carolina. Currículo e formação do profissional do lazer. Revista Brasileira de Ciências do Esporte, v. 23, n. 1, p. 123-130, set. 2001. Disponível em: http://www.rbceonline.org.br/revista/index.php/RBCE/article/view/327/286>. Acesso em: 07/05/2012.

MELO, Victor Andrade de. Lazer e Educação Física: problemas historicamente construídos, saídas possíveis - um enfoque na questão da formação. In: WER- 
NECK, Christianne Luce Gomes, ISAYAMA, Hélder Ferreira (orgs.). Lazer, recreação e Educação Física. Belo Horizonte, Autêntica, 2003.

PINTO, Leila Mirtes Santos de Magalhães. Formação de educadores e educadoras para o lazer: saberes e competências. Revista Brasileira de Ciências do Esporte, v. 22, n. 3, p. 53-71, maio 2001. Disponível em: < http://www.rbceonline.org.br/revista/index.php/RBCE/article/view/383/327>. Acesso em: 07/05/2012.

VALENTE, Márcia Chaves. A disciplina recreação e lazer no currículo de formação de profissionais de Educação Física: o que dizem e fazem professores em universidades do Nordeste do Brasil. Dissertação (Mestrado em Educação Física) - Faculdade de Educação Física, Universidade Estadual de Campinas, 1993.

\title{
CLASS PROGRAMS WITH THE WORD “LEISURE" IN CURITIBA'S HIGHER EDUCATION INSTITUTIONS: DIFFERENCES AND SIMILARITEIS
}

\begin{abstract}
This work has the objective of identify the possible differences and similarities between the disciplines with the term "leisure" in three different institutions in Curitiba. Selected courses in Physical Education and the criterion of choice of subjects was the presence of the word "pleasure" in the title. We noticed differences in relation to workload, number of disciplines, using different terms and types of training that are intended. As similarities, we observe the predominance of disciplines and courses of Bachelor study the history of leisure. Finally, we indicate analysis of teaching plans and teaching practices to better deepening.
\end{abstract}

Keywords: Formation. Leisure. University.

\section{PLAN DE ESTUDIO DE ASIGNATURAS CON EL TERMINO "OCIO" EN LAS INSTITUCIO- NES DE EDUCACIÓN SUPERIOR DE CURITIBA: DIFERENCIAS Y SIMILITUDES}

\section{RESUMEN}

Tratamos de identificar posibles similitudes y diferencias en los menús de las disciplinas con el término "ocio" en tres universidades de Curitiba. Cursos seleccionados en la Educación Física y el criterio de selección de los temas fue la presencia de la palabra "placer" en el título. Nos dimos cuenta de las diferencias en relación a la carga de trabajo, número de disciplinas, utilizando diferentes expresiones y tipos de formación que se destinan. Como similitudes, se observa el predominio de las disciplinas y campos de estudio Licenciatura en la historia del ocio. Por último, se indica el análisis de planes de enseñanza y prácticas docentes para una mejor profundización.

Palabras clave: Formación. Ocio. Universidad.

Endereço para correspondência: taliassis@gmail.com 